\title{
Diplomacia Pública y Marca Ciudad como estrategias de comunicación global
}

\author{
Marcela Pizarro \\ mpizarro@austral.edu.ar
}

Escuela de Posgrados en Comunicación, Facultad de Comunicación, Universidad Austral.

El objetivo de este número especial de Austral comunicación es debatir sobre una de las cuestiones que ha tenido escaso desarrollo académico en el mundo hispanohablante, dentro del área de estudio de la Comunicación Global o Internacional, como se sigue denominando en algunos textos académicos anglosajones. Nos referimos, concretamente, a las disciplinas de Diplomacia Pública y Marca Ciudad, ambas entendidas como estrategias de comunicación exterior.

La globalización ha modificado el escenario político internacional y las relaciones de poder entre los estados y demás actores globales. Esto impacta de manera directa en las formas de comunicar y, por lo tanto, en las investigaciones y estudios realizados en el campo de estudio de la Comunicación Global. En este sentido, la Diplomacia Tradicional o Clásica tiene que complementarse con la Diplomacia Pública, en la que surgen nuevos actores internacionales (organizaciones privadas, del Tercer Sector, movimientos terroristas, ciudadanos, think tanks, ciudades, municipios, etc.), que realizan acciones de carácter internacional y promueven una comunicación estratégica bidireccional, participativa y colaborativa.

En este contexto, el artículo de María Teresa La Porte está dedicado a los think tanks y su "nuevo poder de influencia". Para esta estudiosa del tema, los think tanks son actores de diplomacia pública en un escenario global de cambio e incertidumbre debido a la tarea que realizan de "ofrecer soluciones novedosas e identificar tendencias de futuro". Desde su nacimiento, "han intentado influir y conseguir que sus ideas sean adoptadas por decisores y públicos generando climas de opinión e impactando en los procesos de decisión política". Para ello, es necesario que lo hagan siguiendo una comunicación estratégica que incluya una mentalidad colaborativa, lo que significa evolucionar de una información estratégica de "posicionamiento unilateral de ideas" hacia un enfoque de "generación conjunta de ideas", en el que resulta crucial la participación de otros actores sociales para que la comunicación sea efectiva. En este sentido, la tesis de la profesora de la Universidad de Navarra es que "el fomento de la participación y 
Marcela Pizarro

Diplomacia Pública y Marca Ciudad como estrategias de comunicación global

colaboración de los ciudadanos con las organizaciones favorece la escucha, la reflexión y el debate de las propuestas. En ese contexto, la influencia entendida como aceptación libre de ideas tiene más posibilidades de prosperar", en especial en los think tanks. De ahí que el objetivo principal de su investigación es el de "examinar si las estrategias de comunicación que habitualmente desarrollan algunos de los think tanks con mayor prestigio para difundir sus ideas siguen las nuevas pautas determinadas por la participación y la colaboración". Con este propósito, la autora entrevistó a los responsables de comunicación de ocho think tanks globales y con mayor impacto público, ubicados en Washington DC. Entre las conclusiones a las que llega, destaca que quienes gestionan la comunicación desarrollan, en mayor medida, estrategias participativas y de "cocreación de contenidos" con los públicos selectos que consideran "colaboradores" directos, y tienden a mantener prácticas de "posicionamiento de ideas" con la ciudadanía en general y no modelos de comunicación participativa o colaborativa. Este tipo de comunicación lo circunscriben solo hacia aquellos con los que existe una relación laboral.

En un segundo artículo, el profesor Juan Luis Manfredi Sánchez parte de la premisa de que las ciudades, en su aspiración por convertirse en globales, son el corazón de la Diplomacia Pública y actores privilegiados del escenario internacional por diversas razones: su nueva estructura demográfica, la transformación del poder político y económico, el impacto del cambio climático y el empoderamiento ciudadano. Así, plantea una serie de preguntas novedosas en este campo de estudio, entre otras: “¿Cómo han desarrollado las ciudades sus estrategias de diplomacia pública en el marco de una gobernanza multinivel? ¿Se trata de estrategias alineadas con los gobiernos o independientes? ¿Se constituyen redes y alianzas o actúan de forma independiente? ¿Hasta qué punto las estrategias se alinean con el interés de los Estados? ¿Cómo se organiza el activismo para mejorar su capacidad de incidencia política? ¿De qué modo la gobernanza del cambio climático empodera a la ciudad en la gobernanza multinivel?".

El mérito de su investigación es que examina unas 50 iniciativas de diplomacia pública de ciudades para conocer tanto sus recursos, rasgos, prácticas como los mecanismos de colaboración público-privada y el grado de incidencia política en asuntos internacionales. A su vez, Manfredi Sánchez ordena la actividad política comunicativa internacional de las ciudades en tres ejes (economía, cultura y política) y, por último, elabora una tipología de diplomacia pública de ciudades que permite establecer tanto patrones de comportamiento entre las acciones de diplomacia pública urbana, como construir una teoría comunicativa de la diplomacia urbana. Un aporte muy interesante a los varios que ya cuenta su producción científica sobre este tema.

En tercer lugar, el profesor Remigio Gonzalo Pisco Sánchez analiza la localidad costera de Manta, en Ecuador, como objeto semiótico que comunica un texto urbano, es decir, un texto de la cotidianidad del ciudadano de Manta. Sin embargo, el autor 
aclara que su propósito no es proponer una lectura semiótica abierta de la ciudad, "sino más bien delinear y aproximar un discurso cohesionador de identidad ciudadana". Para ello, también indagará sobre las percepciones de sus habitantes con el objetivo de construir una marca territorial o marca ciudad. Los antecedentes de esta investigación se encuentran en dos trabajos anteriores realizados por Pisco y un equipo de profesores de la Universidad Laica Eloy Alfaro de Manabí: en el primero analizaron el rebranding de Manta después del grave terremoto que tuvo lugar en abril de 2016 y destruyó casi por completo la ciudad. Por su parte, en el segundo trabajo, se indaga en los signos visuales de identidad urbana con el propósito de construir un discurso de marca ciudad desde la percepción de sus ciudadanos.

Por último, este número monográfico sobre Comunicación Global no sería completo sin la participación del profesor Gerardo López Alonso, un gran profesional en el ejercicio del periodismo y un querido y brillante maestro en las aulas de la Facultad de Comunicación de nuestra Universidad Austral.

Desde hace más de 25 años, López Alonso imparte la materia Análisis e Información Internacional y he tenido la suerte y el placer de compartirla con él, desde mis inicios en la Facultad. Ha sido para mí un verdadero lujo y aprendizaje verlo explicar, con entusiasmo y conocimiento, los diversos y variados temas de un cambiante escenario internacional cuyos conflictos sociales, económicos y políticos no dejan de sorprendernos cada día y en el que los temas de una nueva agenda global (cambio climático, corrientes migratorias, populismos, conflictos económicos entre potencias, etc.) ponen en riesgo de manera permanente el equilibro de poder entre los países.

La pasión del profesor López Alonso por los temas internacionales se acentuó cuando empezó en la revista Mercado, de la que fue secretario, jefe de redacción, después director $y$, finalmente, propietario. Durante los diez años que trabajó allí pudo dedicar tiempo a los temas internacionales, ("una vocación de toda la vida") y también viajar por casi todo el mundo. Causa asombro y admiración leer en el texto que publica -en esta oportunidad- la enorme cantidad de países en los que cubrió hechos de actualidad y entrevistó a los líderes políticos del momento. Toda esa larga y valiosa experiencia como periodista convierte sus clases en un recorrido intenso y magnífico por el mundo y permite que sus alumnos se introduzcan en lo que pasa más allá de sus fronteras físicas y mentales, y lo reconozcan siempre, cada año, como uno de sus mejores profesores. Su vocación docente y periodística no merma con el paso del tiempo; al contrario, se renueva cada día. Vaya mi agradecimiento por su generosidad y por ser un ejemplo para sus colegas. 